\title{
Development of driving cycle under real world traffic conditions: a case study
}

\author{
A. Geetha, C. Subramani \\ Department of Electrical and Electroincis Engineering, SRM Institute of Science and Technology, India
}

\begin{tabular}{l}
\hline \hline Article Info \\
\hline Article history: \\
Received Jan 18, 2019 \\
Revised Apr 30, 2019 \\
Accepted Jun 26, 2019 \\
\hline Keywords: \\
Driving characteristics \\
Driving cycle \\
Electric vehicle \\
IR sensor \\
Traffic conditions \\
\hline
\end{tabular}

\begin{abstract}
The modeling of a car is essentially done by taking into consideration the driving terrain, traffic conditions, driver's behavior and various other factors which may directly or indirectly affect the vehicle's performance. A vehicle is modeled for given specifications and constraints like maximum speed, maximum acceleration, and braking time, appropriate suspension for the gradient of the road and fuel consumption. Henceforth, a profound study and analysis of different drive cycles are essential. A time dependent drive cycle is a condensed form of data that helps us to determine the time taken to conduct the driving test on the road. This article highlights the development of a real driving cycle in the area of Tamilnadu, India. On-road vehicle's speeds versus time data were obtained along the selected route. The data obtained were analyzed first and then a new driving cycle was developed.
\end{abstract}

Copyright (C) 2019 Institute of Advanced Engineering and Science. All rights reserved.

\section{Corresponding Author:}

C. Subramani,

Department of Electrical and Electronics Engineering,

SRM Institute of Science and Technology,

Kancheepuram, India.

Email: csmsrm@gmail.com

\section{INTRODUCTION}

The automobile sectors are seeking for an alternative which is more efficient in the reduction of oil consumption and global warming. Pollutant free electric vehicles (EVs) are the better solution [1]. Electric cars are the future of the upcoming automobile industry. It is propelled by an electric motor which drives energy from a battery source or fuel cells. The problem with internal combustion engines is not so much in their efficiency but that they burn fossil fuels whose byproducts are in the form of carbon dioxide and carbon monoxide which are slowly destroying the ozone layer and trapping heat in the atmosphere leading to global warming. Electric cars do not use fuel and tend to be very quiet as compared to gasoline or diesel-powered cars.

Before modeling any car with certain characteristics, a lot of things have to be taken into consideration. A drive cycle is one such important area. A "drive cycle" basically represents a vehicle on the road. The drive cycles are generally used to simulate the real-life experience of a car test on the software. This reduces the cost of road tests, time in conducting the tests and the stress and fatigue of the engineer. The basic idea is to transform the real-life driving experience in the test lab to simulation. The drive cycles can be of distance-dependent or time-dependent.

The drive cycle gives us the practical running conditions of a certain area. The driving cycles comprises of many starts, stops and go conditions which seeks both average and instantaneous power supplies. With the help of a drive cycle, we can assess the driving conditions of an area and we can conclude whether a certain car is appropriate for a region or not. Drive cycles give us information about the fuel emissions required for a car and the pollutants emitted. Thus making drive cycle a very important factor while modeling a car [2]. 


\section{DRIVING CYCLE BACKGROUND}

The driving cycle denotes the series of driving vehicle behavior on the given region i.e. plot denoting the speed of the driving vehicle with respect to time. The development of driving cycle in a real time situation is much essential for certain reasons like vehicle pollution control, fuel and energy consumption study etc. the several operating conditions that are categorized in any driving cycle are idle mode, accelerating mode, cruise mode and decelerating mode [3-5].

Synthesized driving cycle is the standard one which comprises of constant acceleration and speed phases alone. These transitions are mostly artificial when compared with the natural driving cycle. The graph that represents the vehicle speed $(\mathrm{km} / \mathrm{h})$ over a period of travelling time $(\mathrm{s})$ is driving cycle. The components of EV are designed by knowing the driving cycle pattern. Generally the driving pattern relies on road type and its condition, traffic conditions and behavior of the driver. There exists many standard driving cycles based on different countriesSome of the popular standard driving cycles are depicted in Figure 1 [6-9].

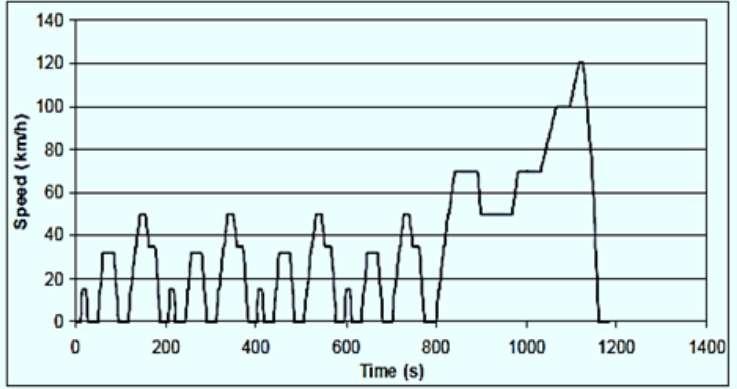

NEDC

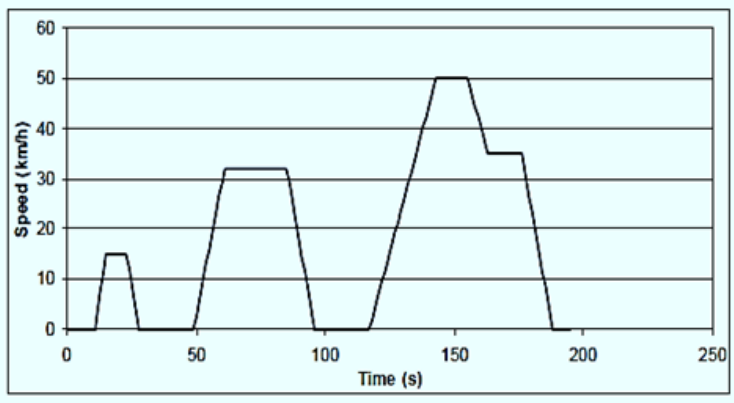

ECE 15

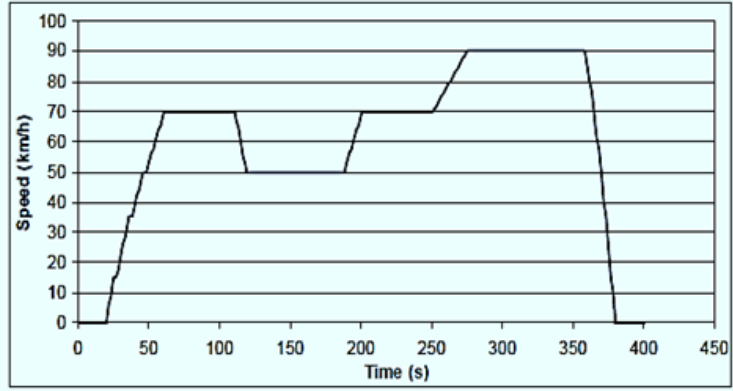

EUDC

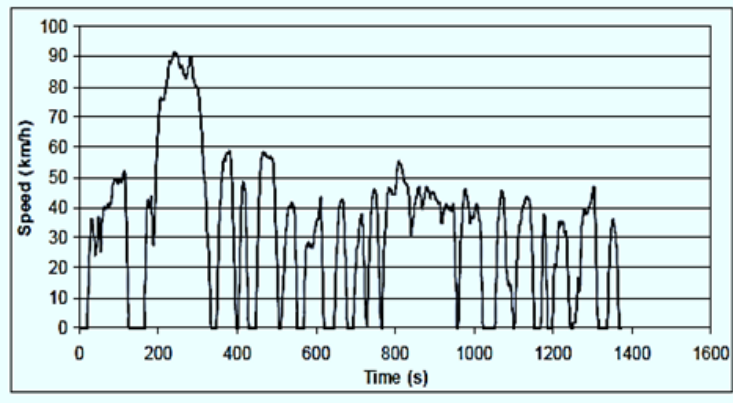

FTP 72

Figure 1. Standard driving cycles

In the case of real world traffic conditions, the actual drive cycle can be generated based on the movement of a vehicle under test. The main use of generation is to simulate the vehicle driving characteristics on the selected area in real and to analyze its energy consumption. This work makes an attempt to generate a real time driving cycle for a heterogeneous traffic conditions.

\subsection{Vehicle dynamics}

Based on the dynamics of vehicle, the force $(F)$ required to run the vehicle should overcome rolling resistance force $\left(\mathrm{F}_{\text {roll }}\right)$, climbing force $\left(\mathrm{F}_{\mathrm{climb}}\right)$ and aerodynamic dragging force $\left(\mathrm{F}_{\mathrm{drag}}\right)$ as given in $(1)$.

$$
\mathrm{F}=\mathrm{F}_{\text {roll }}+\mathrm{F}_{\text {climb }}+\mathrm{F}_{\text {drag }}
$$

The force required to overcome the tire and road friction losses is $F_{\text {roll }}$ as represented in (2). Topological influences on the vehicle should overcome by $F_{\text {climb }}$ given in (3). Vehicle needs some energy to overcome the air friction on the frontal, rear and boundary area of the vehicle $F_{\text {drag }}$ as given in (4).

$$
\begin{aligned}
& \mathrm{F}_{\text {roll }}=\mathrm{m}_{\mathrm{vehi}} * \mathrm{~g}_{\mathrm{acc}} * \mathrm{C}_{\text {roll }} \\
& \mathrm{F}_{\text {climb }}=\mathrm{m}_{\mathrm{vehi}} * \mathrm{~g}_{\mathrm{acc}} * \sin \propto_{\mathrm{inc}}
\end{aligned}
$$




$$
\mathrm{F}_{\text {drag }}=\frac{\left(\rho * \mathrm{~A}_{\text {front }} * \mathrm{C}_{\mathrm{drag} * \mathrm{v}_{\mathrm{veh}}}{ }^{2}\right)}{2}
$$

Here, $\mathrm{m}_{\mathrm{vehi}}$ - vehicle mass $(\mathrm{kg}) . \mathrm{g}_{\mathrm{acc}}$ - acceleration due to gravity $\left(\mathrm{m} / \mathrm{s}^{2}\right) . \mathrm{C}_{\text {roll }}$ - co-efficient of rolling resistance. $\propto_{\text {inc }}-$ angle of inclination (radian). $C_{\text {drag }}$ - drag co-efficient. $\rho$ - air density in $\mathrm{kg} / \mathrm{m}^{3} . A_{\text {front }}-$ vehicle's frontal area $\left(\mathrm{m}^{2}\right)$. $\mathrm{v}_{\mathrm{veh}}$ - speed $(\mathrm{km} / \mathrm{h})$.

The vehicle speed data from the driving cycle plays a crucial role in deciding the force required to drive the vehicle. All locations doesn't have similar pattern of driving as mentioned in standard driving cycle. Hence it is necessary to develop a real time driving cycle to understand the vehicle performances [9-11].

\section{METHODOLOGY}

\subsection{Route selection}

The prominent aspect of developing a real time driving cycle is selecting a route. In Tamilnadu, the major road of $7 \mathrm{~km}$ distance was selected as a route for this study since it possess moderate annual daily traffic MADT. The route map is depicted in Figure 2 and the route details are shown in Table 1. The route was selected based on the traffic density that may result in transient driving characteristics of a vehicle.

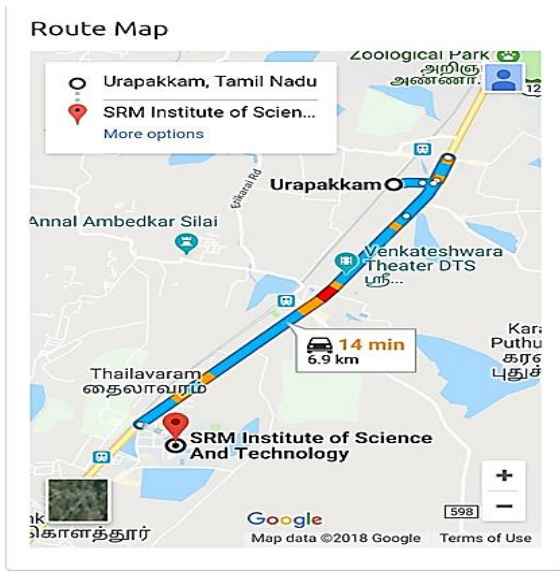

Figure 2. Route map

Table 1. Route details

\begin{tabular}{lll}
\hline Si. No. & Characteristics & Details \\
\hline 1 & Origin & SRMIST, Chennai, Tamilnadu, India \\
2 & Destination & Urapakkam, Chennai, Tamilnadu, India \\
3 & Driving Distance & $6.9 \mathrm{~km}$ \\
4 & Driving Duration & $600 \mathrm{~seconds}$ \\
\hline
\end{tabular}

\subsection{Collection of data}

Here on-board method of measurement is adopted i.e. a device is installed in the test vehicle and a second by second details of the vehicle speed is recorded when the vehicle is driven in a selected route. The data is collected for a period of 30 days as micro-trips. Those micro-trip data were processed and analyzed further for the generation of real world driving cycle [12-14].

\subsection{Generation of driving cycle}

The basic objective of this article is to generate a mono speed versus time graph of a route selected which is considered to represent the traffic conditions of part of a district in Tamilnadu state of a country India. The ultimate scope of generating this driving cycle is to offer a general means of calculating the vehicle's energy consumption and its emissions.

The difficult thing in the generation of driving graph under real world traffic condition is the condensing the larger amount of speed data into a driving cycle with reasonable time duration. There were many recent techniques discussed in the literatures. Most of them deal with the storage of data of a micro trips i.e. speed versus time segments. These data were recorded from the vehicles test runs. Further, it is processed statistically to get the desired cycle [15-17]. 
The DAC, data acquisition control system is considered as shown in Figure 3. It is composed of an infrared optical sensor that is pointing towards the vehicle wheel axle. This sensor measures the number of rotations made by the axle and produces data pulses in the electrical form for each of the rotation. The Arduino incorporated DAC system will collect the data and analyze it. Thus the analyzed data is stored in micro-computer.

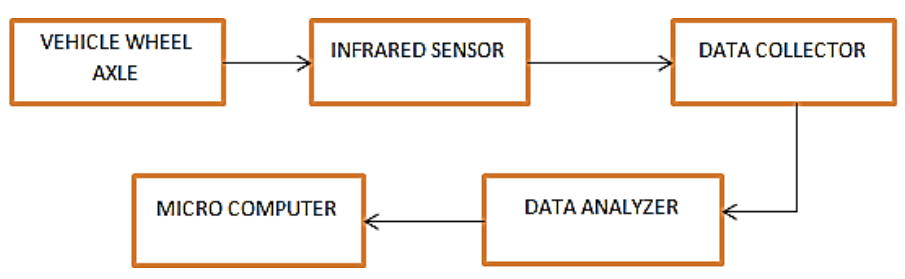

Figure 3. Block diagram of DAC system

\section{EXPERIMENTAL SETUP AND RESULTS}

The whole system is divided into four parts. The first part is to read the values from the IR sensor. The IR sensor has three pins. Two pins are used to supply power to the infrared module. The third pin is the data pin. The data pin sends a digital high to the Arduino each time it senses the obstacle which is the wheel. A thin sheet of aluminium foil is bolted to the inner part of the wheel. This makes it different from the rest of the circumference. When the infrared sensor passes through this part of the wheel, it sends a signal to the Arduino. Figure 4 shows the sensor assembly in the vehicle.

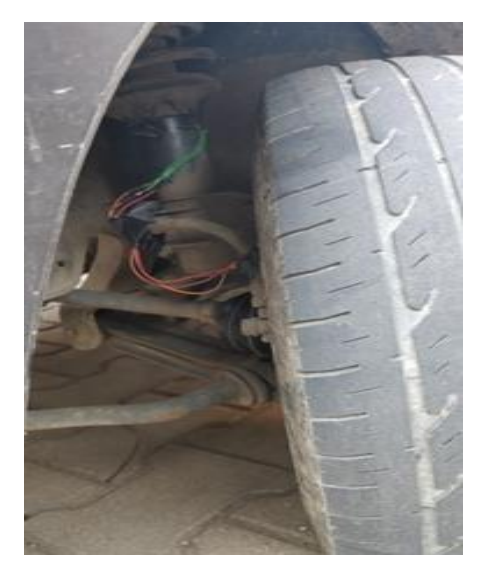

Figure 4. Sensor assembly in the vehicle axle

The time duration between two rotations is measured in microseconds. From this, the rpm is measured and hence the speed. The next part of it is to store these values. This was done by an SD card module. The values obtained by the Arduino were written into this SD card. The values written into this SD card was later viewed using a laptop. The values that were written were stored in order which is of the time, date and the respective speed at that instant.

The real-time clock was another module used to note down the time. It behaves like a clock and gives the time at any instant. It had to be set up first. The current date and time were uploaded into the Arduino with the real-time clock connected. Since the module has an additional 3-volt battery, it runs even when it is not connected to the Arduino and maintains the calculation of time.

A total of three modules are connected to the Arduino. Since a 9-volt battery cannot supply al these modules, we used a power bank to supply the Arduino with power. The power bank supplies a power of 5 Volts and 1 ampere. The total setup is kept in a box which is placed on the front side of the car. The box was placed near the battery to avoid heating of the components. Figure 5 depicts the overall hardware setup of the experiment. 


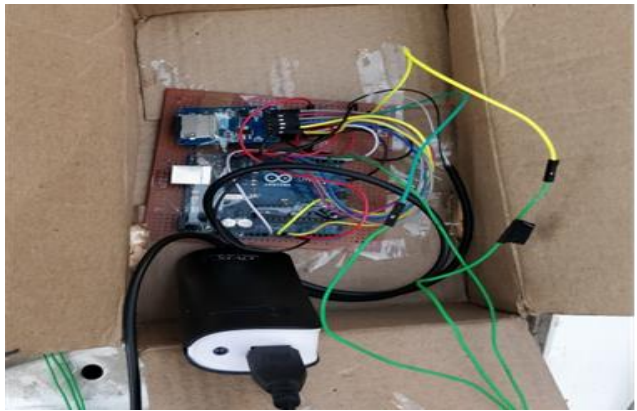

Figure 5. Experimental setup

The sample data is shown in Figure 6 and the graph shown in Figure 7 is the output of the data obtained from the hardware for a period of one day. The distance covered was for seven kilometers. The speed of the vehicle falls to zero after three kilometers due to a signal. The maximum speed obtained was seventy $\mathrm{km} / \mathrm{hr}$. The graph shown is taken for a period of ten minutes. Thus the normal driving pattern is shown for a given period.

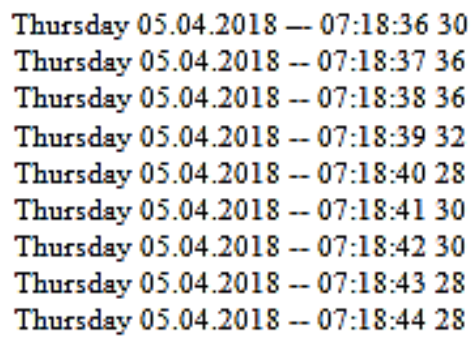

Figure 6. Sample data collected

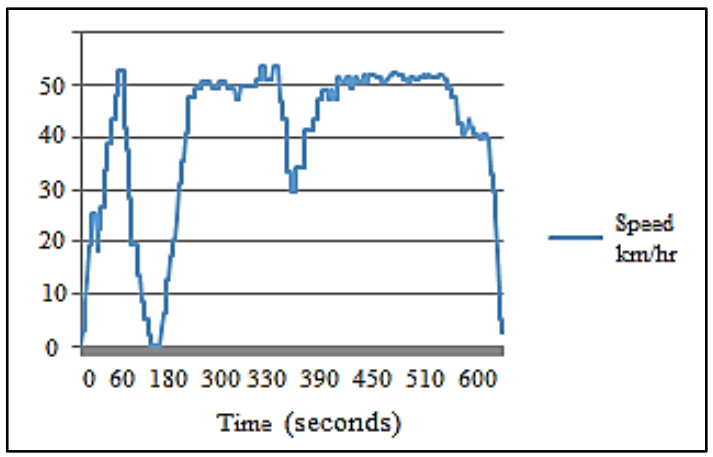

Figure 7. Generated driving cycle

\section{CONCLUSION}

The driving cycle of any area represents the road, the traffic conditions, the people and the driving habits of the habitants of that area. Each area will have a unique driving cycle thereby representing the conditions of that particular area. With this information, we can design an electric vehicle which will be capable to sustain during live driving conditions. We can figure out the amount of time for which the vehicle attains high speeds and the frequency of stops. Thus this paper discusses the experimental setup designed to generate a driving cycle under real world driving conditions in the route selected. All the four operating modes of driving that is acceleration, deceleration, idle and cruising were recorded for a period of time and the average of those micro trips were processed to develop a real driving cycle. 


\section{ACKNOWLEDGEMENT}

Authors like to thank SRM Institute of Science and Technology (SRM Selective Excellence), Kattankulathur, India for supporting this research work.

\section{REFERENCES}

[1] A. Geetha and C. Subramani, "A comprehensive review on energy management strategies of hybrid energy storage system for electric vehicles," International Journal of Energy Research, vol. 41, pp. 1817-1835, 2017.

[2] A. Momenimovahed, et al., "Real-Time Driving Cycle Measurements of Ultrafine Particle Emissions from Two Wheelers and Comparison with Passenger Cars," International Journal of Automotive Technology, vol. 15, pp. 1053-1061, 2014.

[3] G. H. Tzeng and J. J. Chen, "Development of Taipie motor cycle driving cycle for emission and fuel economy," Transportation Research Part D, vol. 3, pp. 19-27, 1998.

[4] A. Geetha and C. Subramani, "An idea for students project work: Energy management in hybridization of energy sources for transportation application," International Journal of Electrical Engineering Education, Dec 2018. Available: https://doi.org/10.1177/0020720918815996.

[5] V. Parekh and V. Shah, "Measurement and Analysis of Indian Road Drive Cycles for Efficient and Economic Design of HEV Component," World Electric Vehicle Journal, vol. 7, pp. 1-12, 2015.

[6] X. Zhang, et al., "A Synthesis of Methodologies and Practices for Developing Driving Cycles," Energy Procedia, vol. 16, pp. 1863-1873, 2012.

[7] G. Zamboni, et al., "On-Road Instantaneous Speed Measurements on Powered Two- Wheelers for Exhaust Emissions and Fuel Consumption Evaluation,” Energy, vol. 36, pp. 1039-1047, 2011.

[8] Krithika V. and Subramani C., "A comprehensive review on choice of hybrid vehicles and power converters, control strategies for hybrid electric vehicles," International Journal of Energy Research, vol. 42, pp. 1789-1812, 2018.

[9] M. Staackmann, et al., "Dynamic driving cycle analyses using electric vehicle time-series data," Intersociety Energy Conversion Engineering Conference, IECEC 1997. Thirty-second Annual IEEE, pp. 2014-2018, 1997.

[10] T. D. Chan and K. T. Chau, "Modern electric vehicle technology," $1^{\text {st }}$ ed., Oxford University Press, 2001.

[11] M. Kamachi, et al., "Development of power management system for electric vehicle "i-MiEV"," International Power electronics conference, IPEC 2010. Annual IEEE, pp. 2949-2955, 2010.

[12] H. Sanghpriya, et al., "Development of real-world driving cycle: Case study of Pune, India," Transportation Research Part D: Transport and Environment, vol. 14, pp. 132-140, 2009.

[13] V. K. Anand, et al., "GPS based methodology for drive cycle determination," SAE Transactions, vol. 114, pp. 233-239, 2005.

[14] A. E. Booth, et al., "A review of vehicular emission models and driving cycles," Proceedings of the Institution of Mechanical Engineers: Part C: Journal of Mechanical Engineering Science, vol. 216, pp. 777-797, 2002.

[15] U. Galgamuwa, et al., "Developing a General Methodology for Driving Cycle Construction: Comparison of Various Established Driving Cycles in the World to Propose a General Approach," Journal of Transportation Technologies, vol. 5, pp. 191-203, 2015.

[16] H. Y. Tong, et al., "Development of a driving cycle for Hong Kong," Atmospheric Environment, vol. 33, pp. 2323-2335, 1999.

[17] M. Ergeneman, et al., "Development of a driving cycle for the prediction of pollutant emissions and fuel consumption," International Journal of Vehicle Design, vol. 18, pp. 391-399, 1997. 